\title{
EXPERIMENTAL INVESTIGATION OF INLET DISTORTION EFFECT ON PERFORMANCE OF A MICRO GAS TURBINE
}

\author{
Alireza Naseri ${ }^{1}$ \\ Department of Aerospace Engineering \\ Amirkabir University of Technology (Tehran Polytechnic) \\ 424 Hafez Ave., Tehran 15875-4413, Iran \\ E-mail: naseri.alireza@aut.ac.ir \\ Shervin Sammak ${ }^{2}$ \\ Center for Research Computing, University of Pittsburgh \\ 3700 Ohara St., Pittsburgh, PA 15261 \\ E-mail: shervin.sammak@pitt.edu \\ Masoud Boroomand \\ Department of Aerospace Engineering \\ Amirkabir University of Technology (Tehran Polytechnic) \\ 424 Hafez Ave., Tehran 15875-4413, Iran \\ E-mail: boromand@aut.ac.ir
}

\author{
Alireza Alihosseini \\ Department of Aerospace Engineering \\ Amirkabir University of Technology (Tehran Polytechnic) \\ 424 Hafez Ave., Tehran 15875-4413, Iran \\ E-mail: aliralih@aut.ac.ir
}

1 Currently at Heat and Mass Transfer Technological Center, Universitat Politècnica de Catalunya, Barcelona, Spain, email: anaseri@cttc.upc.edu (A. Naseri).

2 Corresponding author at Center for Research Computing, University of Pittsburgh, Pittsburgh, Pennsylvania, United States, e-mail: shervin.sammak@pitt.edu (S. Sammak). 


\author{
Abolghasem M. Tousi \\ Department of Aerospace Engineering \\ Amirkabir University of Technology (Tehran Polytechnic) \\ 424 Hafez Ave., Tehran 15875-4413, Iran \\ E-mail: tousi@aut.ac.ir
}

\begin{abstract}
An experimental study has been carried out to determine how inlet total-pressure distortion affects the performance of a micro gas turbine. An inlet simulator is designed and developed to produce and measure distortion patterns at the inlet to the gas turbine. An Air Jet Distortion Generator is used to produce nonuniform flow patterns and total pressure probes are installed to measure steady-state total-pressure distribution at the inlet. A set of wind tunnel tests have been performed to confirm the fidelity of distortion generator and measuring devices. Tests are carried out with the gas turbine exposed to inlet flow with 60degree, 120-degree, and 180-degree circumferential distortion patterns with different distortion intensities. The Performance of the gas turbine has been measured and compared with that of clean inlet flow case. Results indicate that the gas turbine performance can be affected significantly facing with intense inlet distortions.
\end{abstract}

Keywords: Inlet distortion; micro gas turbine; experimental investigation; air jet distortion generator

\title{
1 Introduction
}

Unfavorable effects of non-uniform inlet flow on engine operation have always been encountered in design and development of gas turbine engines. Distorted flow at the inlet can degrade engine performance and reduce engine safe operation range. Inlet flow distortion declines engine performance criteria like engine thrust force and specific fuel consumption (SFC), and in critical cases may even lead to surge phenomena or engine flameout.

Inlet flow distortion may be categorized into four major forms namely: inlet totalpressure distortion, total-temperature distortion, swirl distortion and planer waves. One form of inlet flow distortion or even a combination of different forms may exist at the inlet of a gas turbine engine [1]. The effect of inlet total-pressure distortion on engine operation have been studied earlier in the development of gas turbines and evaluated more than other distortion types.

Inlet total-pressure distortion is defined as the spatial distribution of the total pressure at the inlet of an engine. So that there is one or more distorted zones in the inlet cross section with a total pressure lower than the average. Similar definition can be made for inlet total-temperature distortion in which distorted zones experience higher total 
temperature. Swirl distortion or flow angularity is defined as the swirling flow at the inlet.

These non-uniformities mainly arise from flow field inside the intake system. Engine intake has the role to catch the air from outside flow and deliver it to engine at the required conditions. The nature of the flow inside the intake system and complex aerodynamic interaction between engine and intake system is the major source of the distorted flow at engine inlet.

For years the society of automotive engineers (SAE) S-16 committee has been providing standards which address methodologies for testing and analyzing inlet distortion effects on a gas turbine engine [2-4]. To easily deal with it, adequate parameters should be defined to quantify the inlet flow non-uniformities. Two parameters are defined and widely used to quantify inlet total-pressure distortion. Distortion size is the circumferential size of the distorted zone at the inlet cross section in degrees $(\theta)$ and distortion Intensity is defined as the pressure difference between clean and distorted sections divided by the average dynamic pressure of the flow inside the inlet duct (Eq. (1)).

$$
\begin{aligned}
& D C(\theta)=\frac{P_{0 c}-P_{0 d}}{q_{a}} \\
& D C(\theta)=\frac{P_{0 c}-P_{0 d}}{q_{a}}(1)
\end{aligned}
$$

Where $\mathrm{P}_{0 c}$ and $\mathrm{P}_{0 d}$ are average total pressure of the clean and distorted zones respectively. With this definition, $\mathrm{DC}(60)=0.5$ means existence of one 60 -degree distorted zone with intensity of 0.5 at the inlet cross section.

To evaluate the distribution of the total pressure, local distortion intensity is defined by Eq. (2) for each point in the inlet cross section:

$$
D C_{L}=\frac{P_{0 n}-P_{0 L}}{q_{a}} \quad D C(\theta)=\frac{P_{0 c}-P_{0 d}}{q_{a}} \quad D C(\theta)=\frac{P_{0 c}-P_{0 d}}{q_{a}}(1)
$$

Nominal pressure $\left(P_{0 n}\right)$ in Eq. 2 is the pressure that would uniformly exist at the inlet cross section if no distortion was present.

Many experimental [5-8] and numerical [9-13] works have been carried out to study effect of inlet flow distortion on a compressor performance and stability. The extent to which inlet distortion degrades a compressor's performance, largely depends on the under test compressor's specific characteristics [14]. Reference [2] contains two distinct examples of compressor rig tests including inlet flow distortion which shows quite different results in efficiency losses, from less than $1 \%$ in one case to $1-5 \%$ in another. Most of studies considered effects of inlet flow distortion on a single compressor component rather than a whole gas turbine engine. However it seems to be of great interest to know how the inlet flow distortion affects a whole engine's performance and 
operability. Deterioration in compression component efficiency leads to losses in overall performance of a gas turbine engine in terms of its thrust force and specific fuel consumption.

Kurzke [14] used parallel compressor model together with an engine performance program to numerically simulate inlet distortion effects on a gas turbine engine performance. It states that thermodynamic cycle change due to inlet distortion is generally small and performance loss of a gas turbine engine is mostly because of inadequate reactions of the engine control system. Figure 7 in this reference includes results from numerical simulations that show an engine thrust deficit of about $1 \%$ and SFC increase of about $2 \%$ due to inlet total-pressure distortion with intensities between 0 - 2.8 in the absence of control system reactions [14].

Lee et al. [15] represented an experimental study investigating the effect of inlet totalpressure and swirl distortion on a gas turbine engine in an altitude test facility. Screentype and blockage-type devices are used to simulate total-pressure distortion at engine inlet. Results shows that changing total-pressure distortion intensity from 0.2 to 0.6 can cause the engine thrust force to decrease as large as $10 \%$ and engine SFC to increase about $5 \%$ in some engine RPMs.

Nowadays small gas turbines have found their place in various industrial and research applications. Their small size and ease of use made them very suitable to be used as research facilities in universities. New studies can be done on these small, cheap and easy to use devices instead of large, expensive and sensitive gas turbines, considering that their components and principles are essentially the same as those of large ones.

This paper represents an experimental study to investigate the effect of steady-state inlet total-pressure distortion on performance of a micro gas turbine. Using an existing micro gas turbine test cell, Direct-Connect test method (to be defined in following section) is used. An inlet simulator is designed and developed to produce and measure distortion patterns at the engine inlet. Total-pressure distortion is produced using an array of forward facing air jets mounted inside an inlet duct, ahead of the engine face. Engine performance in terms of its thrust force and SFC, together with compression component efficiency has been measured for engine operating under inlet flow distortion and compared with those of clean inlet flow.

\section{Engine Test}

Engine tests play a major role in design and development of a gas turbine engine and provide the necessary information needed for evaluation of the engine performance and lifetime in the design process.

Engine tests can be categorized into three groups: performance, operability and durability tests. In the performance tests engine performance parameters are measured and their behavior at different working conditions are evaluated. While operability tests focus on the evaluating engine safe operation range and stability margins. Durability tests deal with the structural integrity of the system components and issues including high and low cycle fatigues [16]. 
Engine tests might be performed in either a wind tunnel or turbine engine test cell regarding to the test type and procedure. A turbine engine test cell usually includes a thrust stand on which the engine is mounted and a series of instruments to measure the necessary parameters during the test. An air supply duct also is often used in front of the engine. A number of test techniques might be used to simulate the real operating conditions during the tests.

Direct-connect test method is the most commonly used turbine engine test technique due to adequate test opportunities and generally lower cost. It is named after the direct connection between the turbine engine and the air supply duct. Reference [17-18] contains a well-made description of direct-connect test method.

In the absence of the intake system, particular techniques should be used to artificially reproduce the real flow condition at the inlet to the engine. An Inlet Simulator has the role to produce non-uniform flow patterns which simulates the distortions associated with the intake system. The unit should be capable of producing predetermined distortion patterns at the engine inlet. These patterns are usually obtained from evaluating the particular intake system that is to be used, in either a wind tunnel test or with CFD analyses.

Techniques for producing inlet total-pressure distortion are divided into two general groups [17]:

- Techniques that use aerodynamic blockage of the flow to make total pressure drop at some particular areas.

- Techniques that use momentum exchange with secondary air jets to either add or reduce total pressure at some particular areas

The first idea is present in one of the most basic techniques which uses distortion screens at the upstream of the engine. When incoming flow passes through the screens, aerodynamic blockage causes low pressure wakes to be formed at the rear of the screen. These wakes are stronger in areas with more condensed mesh, so total pressure has a spatial distribution at the rear of the screen. Screens with different mesh structures produce different inlet distortion patterns. An example of the distortion screens with different mesh structure and the associated Direct-Connect test setup is seen in the Fig. 1. 


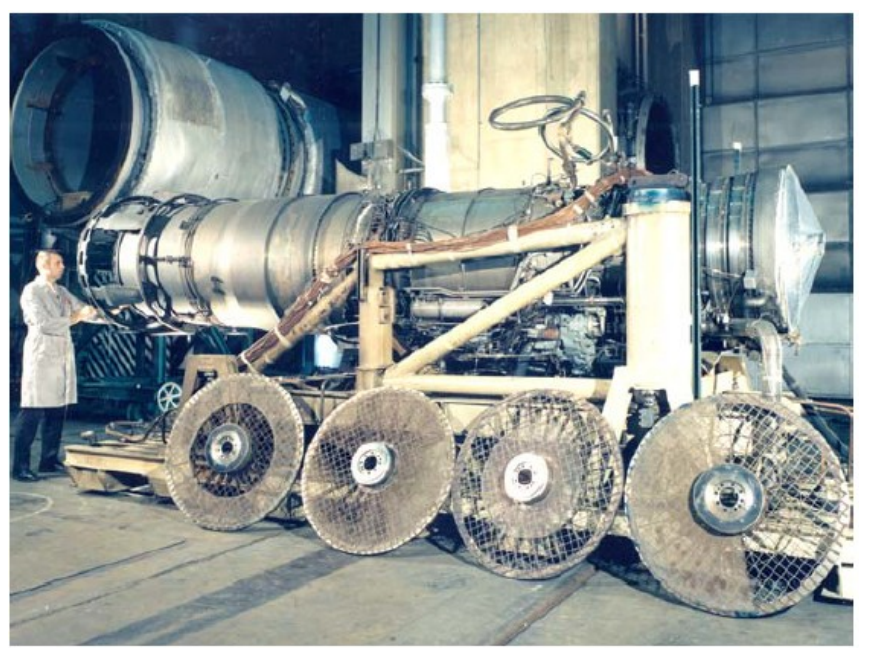

Figure 1: Distortion Screens for direct-connect test setup (Ref. 18)

The great simplicity of the distortion screen method has made it very attractive for engine tests with steady-state inlet flow distortion. It does not contain any moving part and can be easily mounted in the direct-connect test setup upstream of the engine. But the screen method establishes two major disadvantages. First, each distortion screen corresponds to a unique distortion pattern, while performing engine performance and operability tests require a large number of distortion screens with different mesh structures. Design and fabrication of each individual screen may take excessive amount of time and charge a large cost to engine developer. The second major difficulty of using distortion screens is changing distortion patterns during the test. To conduct this, test should be interrupted and the engine shut down, test setup should be disassembled, new screen is to be installed and then test can continue. It is obvious that such a test procedure is very time consuming and imposes very high expenses to accomplish the necessary tests. More advanced techniques usually utilize some variable geometries that can produce different distortion patterns using flexible configurations. A description on some of these techniques and their relevant test setups can be found in [17-18].

The second basic idea uses secondary air jets to produce a non-uniform flow inside the inlet duct. Such devices are usually called Air Jet Distortion Generator (AJDG). Each forward-facing air jet mounted inside the inlet duct produces a local pressure drop due to momentum exchange with the incoming flow. By injecting an array of such air jets, the AJDG will be able to produce different distortion patterns by establishing different arrangements of air jets. So different distortion patterns could be produced without interrupting the test and the patterns can be adjusted remotely. Figure 2 shows a schematic view of the AJDG and inlet simulator duct. 


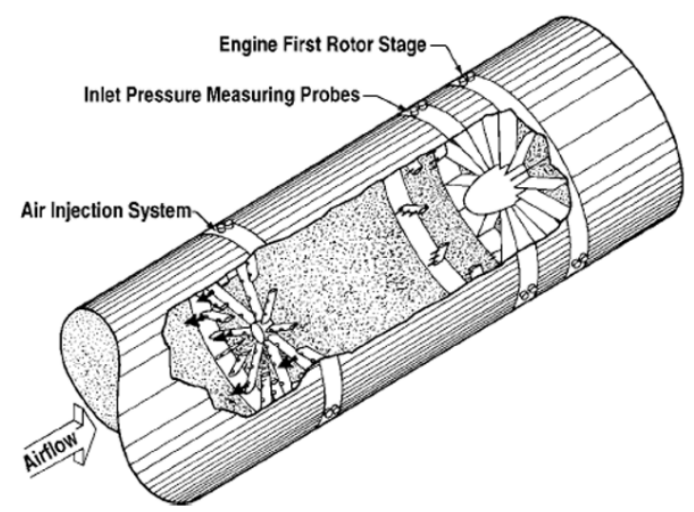

Figure 2: Air Jet Distortion Generator in a direct connect test setup (Ref. 18)

Two reports on the development of AJDG can be found in literature. One is developed by Arnold Engineering Development Center and reported in references $[19,20]$. It used 24 struts to hold 56 air jets inside the inlet duct. Struts are distributed inside the inlet cross section in every 15 degrees and two or three air jets are mounted on each strut. Air jets are connected to a pressurized air supply system through 56 individually controlled valves. 48 total pressure probes were mounted on eight rakes to measure the total pressure distribution at the engine face. A control system has been used to compare the delivered distortion pattern with the desired one and adjust the AJDG configuration to reach the desired pattern [19-20].

Another AJDG test setup was developed by NASA [16] using 54 air jets. Six valves were used to control groups of nine air jets. Each group covered a 60-degree zone at the inlet cross section. The system also was used to produce time-variant inlet distortions by use of high-response servo-valves [16].

\section{Experimental Setup}

\subsection{Micro Gas Turbine Test Cell}

Engine performance tests were carried out in the micro gas turbine test facility at Amirkabir University of Technology (Tehran Polytechnic). The test cell includes an Olympus HP micro gas turbine and a series of instruments to accurately measure its performance criteria. Figure 3 shows the micro gas turbine test cell outlook. 


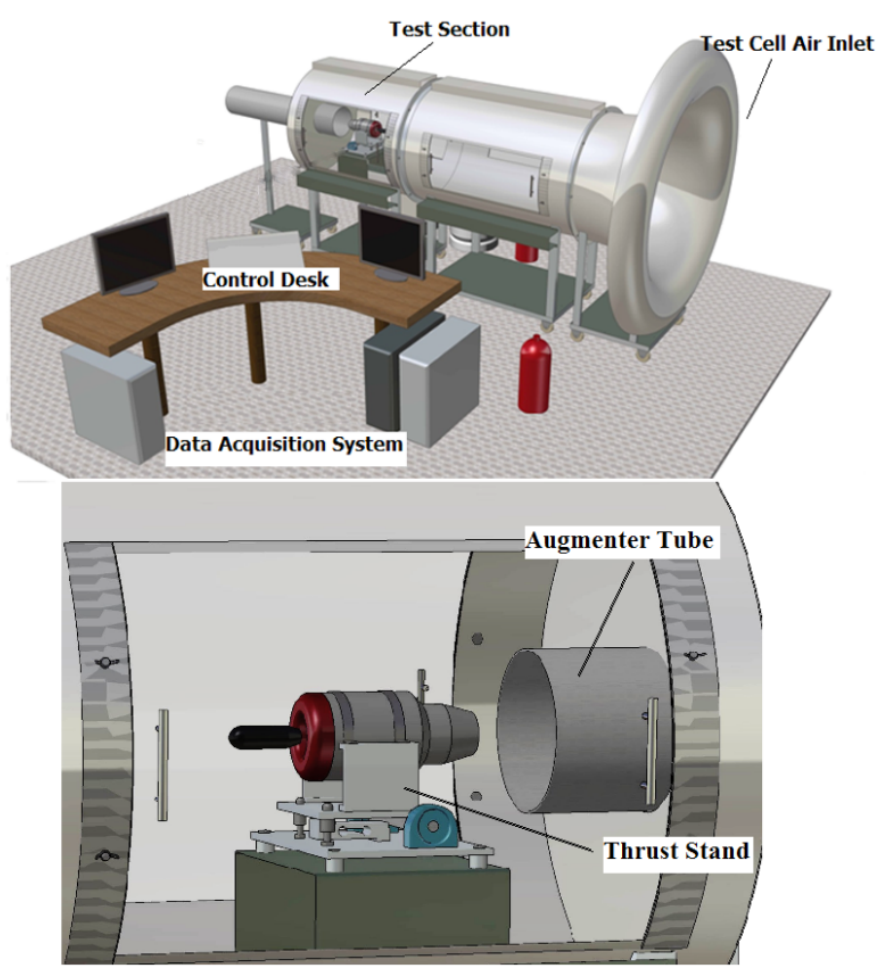

Figure 3: outlook of the micro gas turbine test facility at Tehran Polytechnic

A thrust stand using a SCAIME AQ load cell with an accuracy of $0.017 \%$ of the full scale range is used to measure engine thrust force. Total combined error of thrust measurements is not more than $1 \%$ of the measured value.

Pressure and temperature sensors are mounted inside the engine, to measure compressor's pressure ratio and its efficiency. Compressor outlet pressure is measured using a Kistler 4007BA high temperature pressure sensor with an accuracy of $0.1 \%$ of the full scale range. For temperature measurements, a well calibrated RTD sensor with an accuracy of $0.5^{\circ} \mathrm{C}$ in the operating temperature range was used.

A digital scale connected to a computer is used for instantaneous measurement of the fuel reservoir weight. A computer software has been employed to calculate engine SFC at every instant. The accuracy of the SFC measurements is $1 \%$ of measured values.

All sensors are connected to computer via ADVANTECH PCI-1713 A/D card. Measuring instruments were calibrated before each test to ensure validity of the measurements.

Figure 4 shows the results of the engine performance test which was carried out without considering inlet distortions. The inlet simulator was not installed in front of the engine and the tests were performed at atmospheric conditions of $\mathrm{T}_{\mathrm{a}}=18{ }^{\circ} \mathrm{C}$ and $\mathrm{P}_{\mathrm{a}}=1.019$ bar. The variation of engine thrust force and compressor outlet pressure against engine RPM are presented in this picture. 


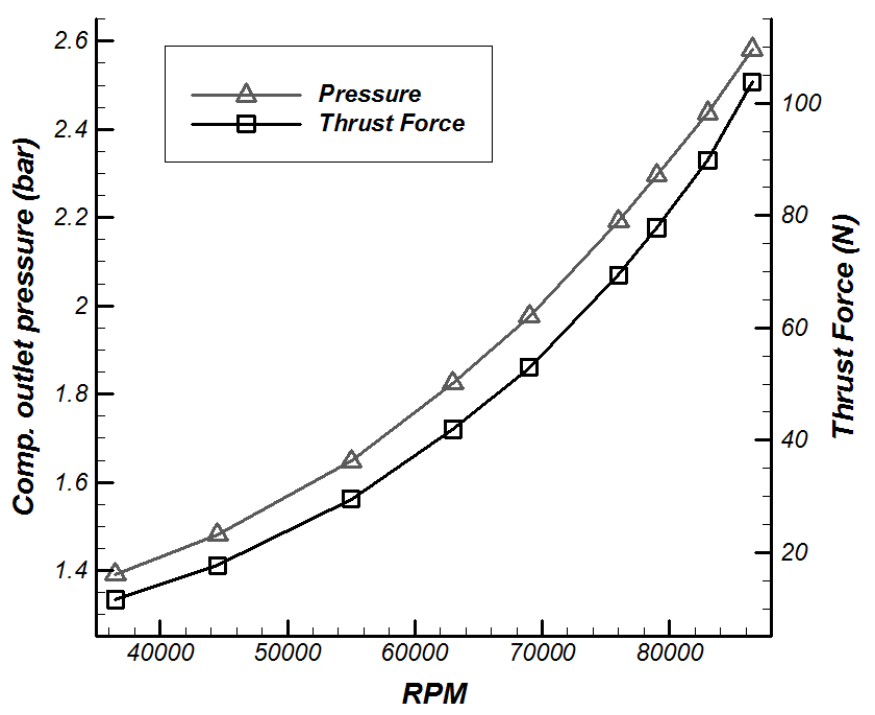

Figure 4: Engine performance test results without inlet distortion

\subsection{Inlet Simulator}

Direct-connect test technique has been used for tests with inlet flow distortion. The developed inlet simulator consists of a directly-connected air supply duct, a distortion generator unit ahead of the engine face and a matrix of total pressure probes at the end of the duct, close to engine entry. Figure 5 shows a schematic view of the engine and the inlet simulator.

Test Cell Wall

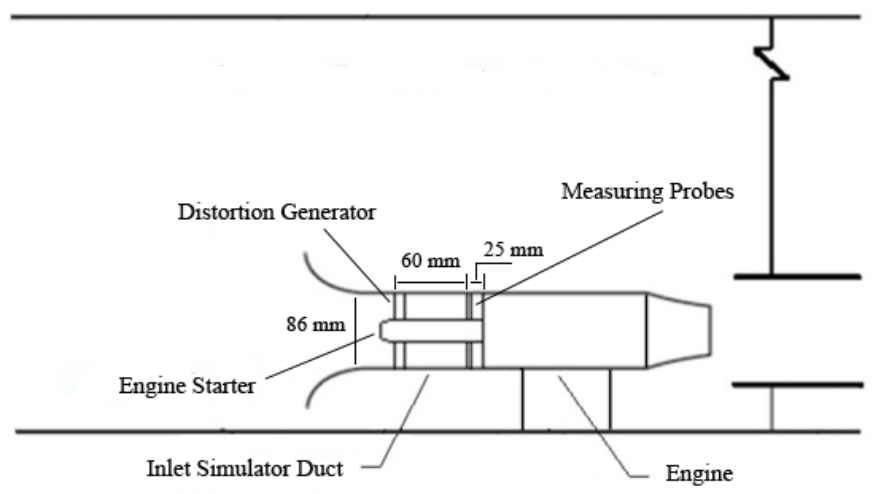

Figure 5: Schematic view of the experimental setup used in the tests

Secondary air jets are used to produce non-uniform flow inside the inlet duct; so called an Air Jet Distortion Generator (AJDG). It includes an array of forward facing air jets, each producing a local pressure drop due to momentum exchange with the incoming flow. Thirty air jets are mounted on six rakes. When each rake with all five mounted air jets turns $\mathrm{ON}$, it produces pressure drop in a zone of 30-degree circumferential area. Each pair of rakes is connected to one control valve, so the system is able to produce 
distorted sections of 60-degree, 120-degree and 180-degree. Radial distortion can also be produced by turning $\mathrm{ON}$ air jets on the same radius.

A Bellofram T-10 highly accurate pressure regulator is used to set the upstream pressure of the air jets. Higher upstream pressure causes higher air jet speed and consequently more pressure drop in the distorted zone and higher distortion intensity.

Twelve pitot-tube probes are employed to measure total pressure distribution at the inlet cross section. Probes are mounted on six struts holding them on two rings in a way that each probe samples an equal area portion of the inlet duct cross section. Figure 6 shows AJDG and measuring probe's locations inside the inlet simulator duct.

Small size of the engine inlet requires very small pressure probes that have the minimum intrusion on the flow field. Such small total pressure probes with only a few millimeters of diameter have been fabricated in the laboratory and installed inside the inlet duct. Wind tunnel tests have been carried out to calibrate the measuring devices and check the fidelity of the pressure probes. Each probe have been evaluated individually in the wind tunnel and certified only if a high fidelity is shown.

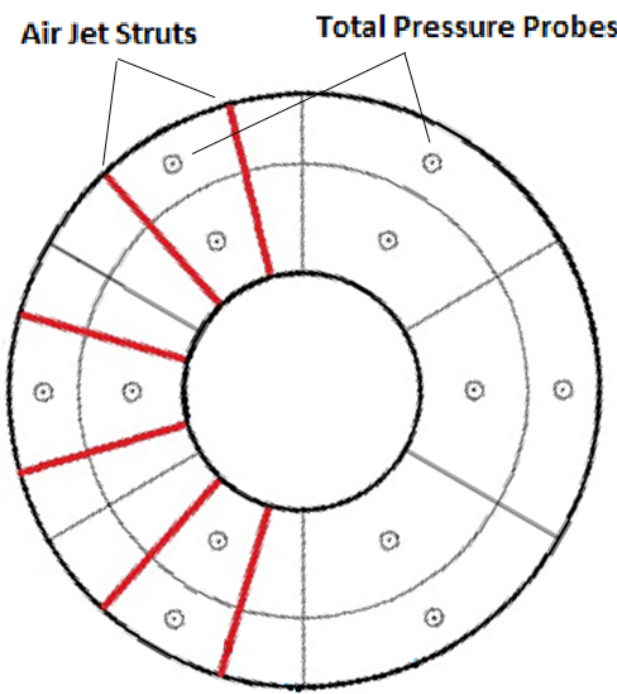

Figure 6: Air jets and measuring probe's location in the duct cross section

Figure 7 shows the AUT micro gas turbine test cell and the experimental apparatus used in this study. The inlet simulator installed in front of the engine, engine thrust stand and the AJDG controlling valves are seen in the picture. 


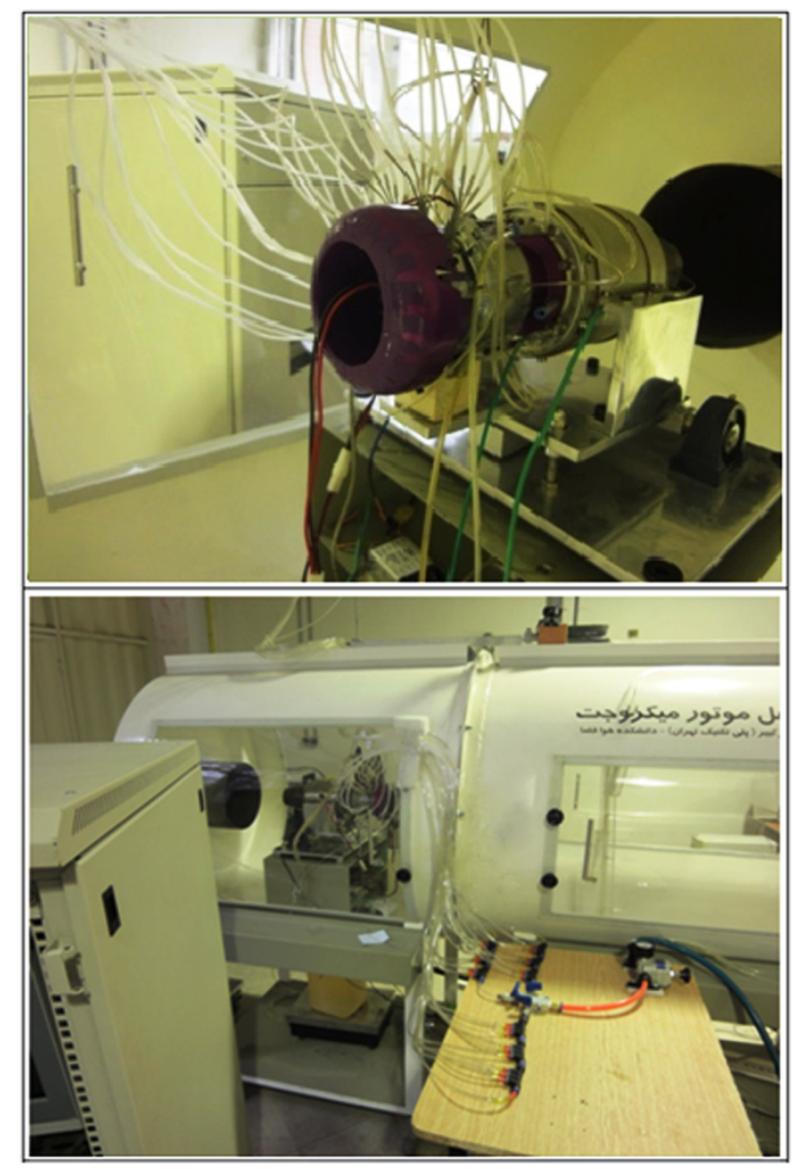

Figure 7: Experimental Apparatus used in this study

\section{Validation Tests}

A series of wind tunnel tests have been performed to verify proper operation of the inlet simulator including distortion generator and measuring probes. Measuring probes were connected to Omega PX138 pressure transducers with an accuracy of $0.2 \%$ of the full scale range, and their operations have been evaluated several times in different tunnel speeds to check measured pressures with the reference values.

The operation of the distortion generator unit was also evaluated in the wind tunnel tests by producing different distortion patterns inside the inlet duct. The size and intensity of the distorted zone is easily under control by means of controlling valves and pressure regulator. Figure 8 shows circumferential distortion patterns produced inside the inlet duct during wind tunnel tests. Pictures are contour plots of the local distortion intensity inside the inlet duct which are measured by the pressure probes. Local distortion intensity is defined by Eq. (2) for each point where a probe is located. In other points it is calculated with a linear interpolation. Total pressure of flow upstream the wind tunnel test section is used as the nominal pressure $\left(P_{o_{n}}\right)$ in Eq. (2). The flow velocity in wind tunnel was $35 \mathrm{~m} / \mathrm{s}$ which is very similar to the velocity that occurs at the inlet of the gas turbine engine used in this work. 


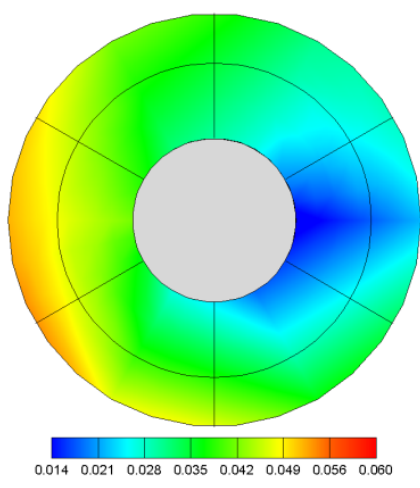

a. Clean Inlet

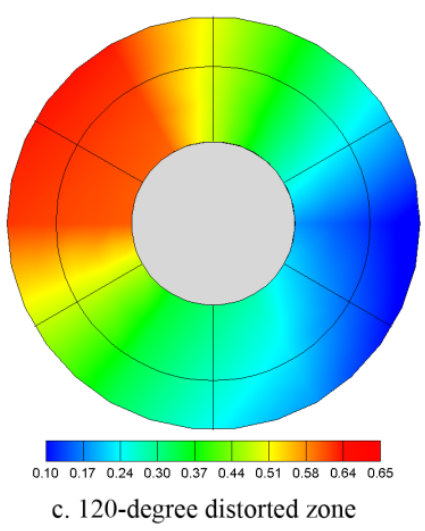

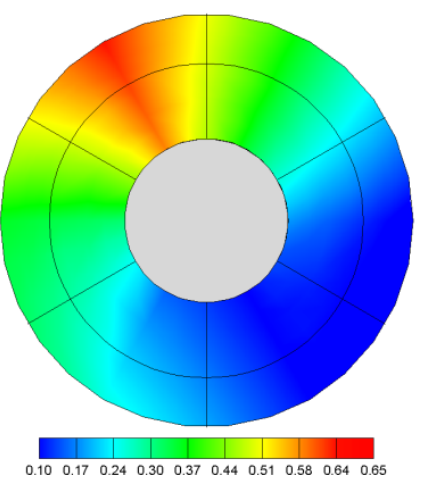

b. 60-degree distorted zone

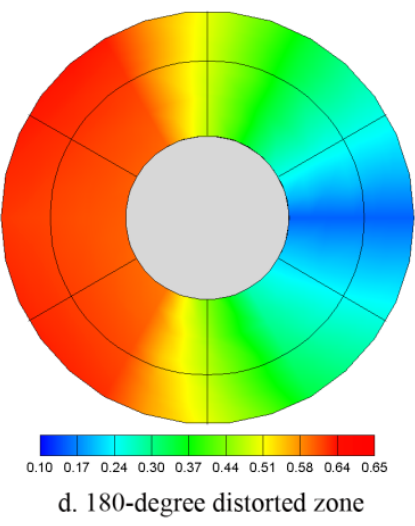

Figure 8: Distortion patterns inside the inlet simulator, measured during wind tunnel tests

Figure $8 a$ shows the total pressure distribution at the clean inlet flow case. The maximum measured value for the local distortion intensity at clean flow is 0.05 . It indicates the adequate uniformity of the flow at the clean inlet case. Figure $8 \mathrm{~b}$ shows a 60-degree distortion pattern. The local distortion intensity which is measured by the pressure probes in the distorted zone is 0.65 . It is seen that even in the clean section total pressure is somewhat dropped from the nominal pressure. Figure $8 \mathrm{~b}, 8 \mathrm{c}$ and $8 \mathrm{~d}$ illustrates 60-degree, 120-degree and 180-degree circumferential distortion patterns respectively.

Wind tunnel test results show the ability of the system to produce distortion patterns with different size and intensities. Tests repeated several times and repeatable patterns were observed.

\section{Results and Discussion}

Tests have been carried out with engine exposed to circumferential distortion at sectors of 60, 120 and 180 degree. In each case, distribution of total pressure was measured at the engine inlet and distortion intensity was obtained by using Eq. (1). All tests are conducted at a constant engine RPM of 40000 . Each test was repeated two times to ensure the accuracy of results. Table 1 shows engine performance test results with clean air flow. 
Table 1: Engine performance with clean inlet flow

\begin{tabular}{|l|c|}
\hline Engine RPM & 40000 \\
\hline Compressor Pressure Ratio & 1.201 \\
\hline Compressor Outlet Temperature (K) & 319 \\
\hline Compressor isentropic Efficiency (\%) & 58.1 \\
\hline Engine Thrust Force (N) & 14.2 \\
\hline Engine SFC (Kg/N.hr) & 0.415 \\
\hline Engine EGT (K) & 650 \\
\hline
\end{tabular}

There is a slight difference between the results in table 1 for clean inlet flow and results shown in Fig. 1 for 40000 RPM. It is the effect of installation of the new inlet duct in front of the engine (without distortion producing) on engine performance.

Pressure distribution was measured for clean inlet flow to check the flow uniformity. The maximum value for local distortion intensity was about 0.05 which is a low value and indicates adequate uniformity of flow at clean inlet case. Figure 9a shows the total pressure distribution at the clean inlet flow. Performance tests are accomplished for distortion intensities between 0.3 and 0.7. Figure 9 shows the distortion patterns produced at the engine inlet during engine performance tests. All pictures are contour plots of local distortion intensity. The air supply duct is directly fed from the atmosphere so the atmospheric pressure is used as the nominal pressure $\left(P_{0_{n}}\right)$ in the Eq. (2). 


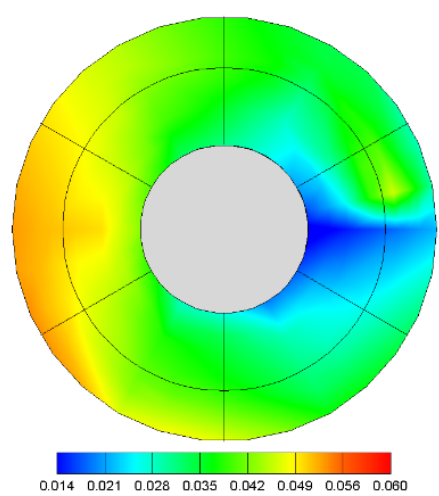

a. Clean Inlet

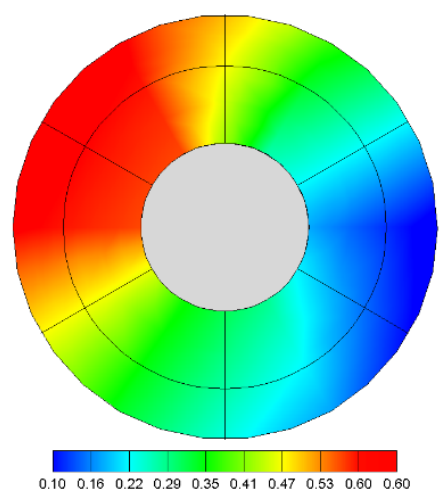

c. 120-degree distorted zone

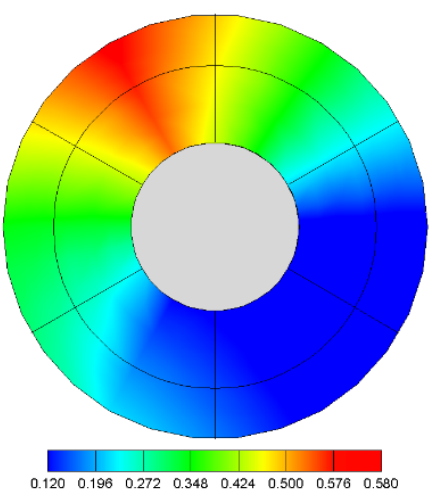

b. 60-degree distorted zone

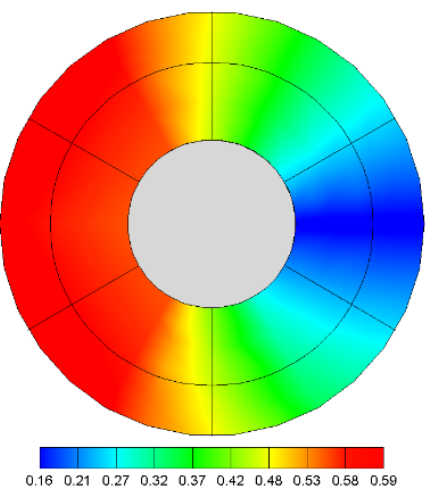

d. 180-degree distorted zone

Figure 9: Total pressure distribution measured at the inlet of the engine

The variation of engine thrust force with distortion parameters is depicted in Fig. 10. It's seen that engine thrust force decreases with increase in both distortion size and intensity. Increasing distortion size from 120 degree to 180 degree causes an approximately constant increase in thrust deficit of about $1.5 \%$. A similar trend can be seen for changing distortion size from 60 degree to 120 degree.

With 60-degree distorted section, engine performance did not get affected, in the order of measurements accuracy, for distortion intensities less than $D C(60)=0.5$. Further increase in distortion intensity results in $1.5 \%$ reduction in thrust force for $D C(60)=0.58$ and $2.5 \%$ for $\mathrm{DC}(60)=0.68$.

Engine thrust force decreases between 1\% - 5\% for DC(120) varying between 0.3 and 0.7. Variation of $\mathrm{DC}(180)$ between 0.3 and 0.64 results in a thrust deficit between 2.5 $5.5 \%$. 


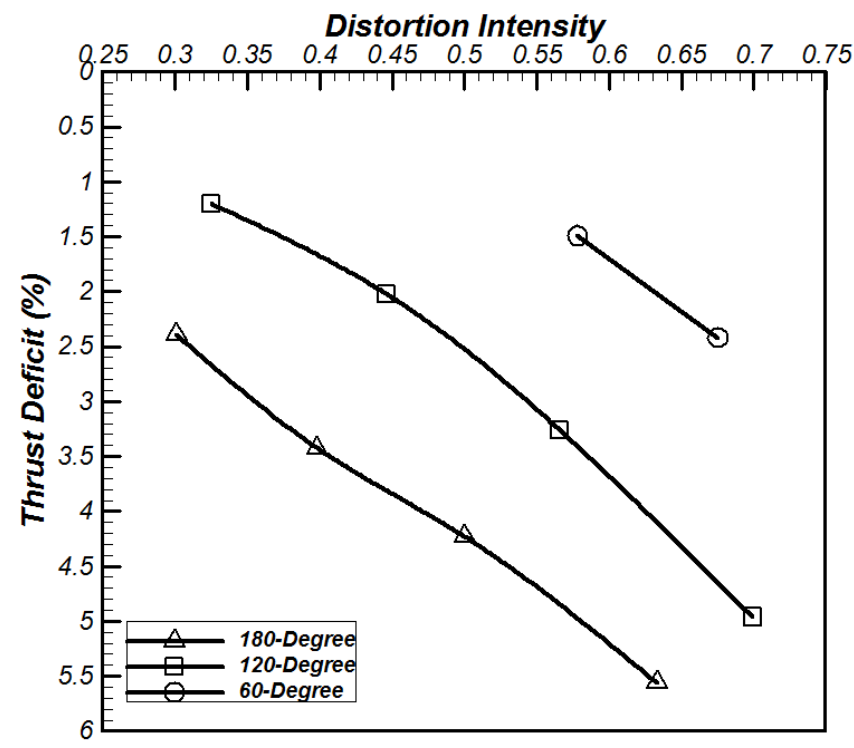

Figure 10: Engine thrust deficit due to inlet distortion

Figure 11 shows similar trend for specific fuel consumption against distortion size and intensity. As it is seen, SFC increases about $7.5 \%$ in the most crucial case which is $\mathrm{DC}(180)=0.64$.

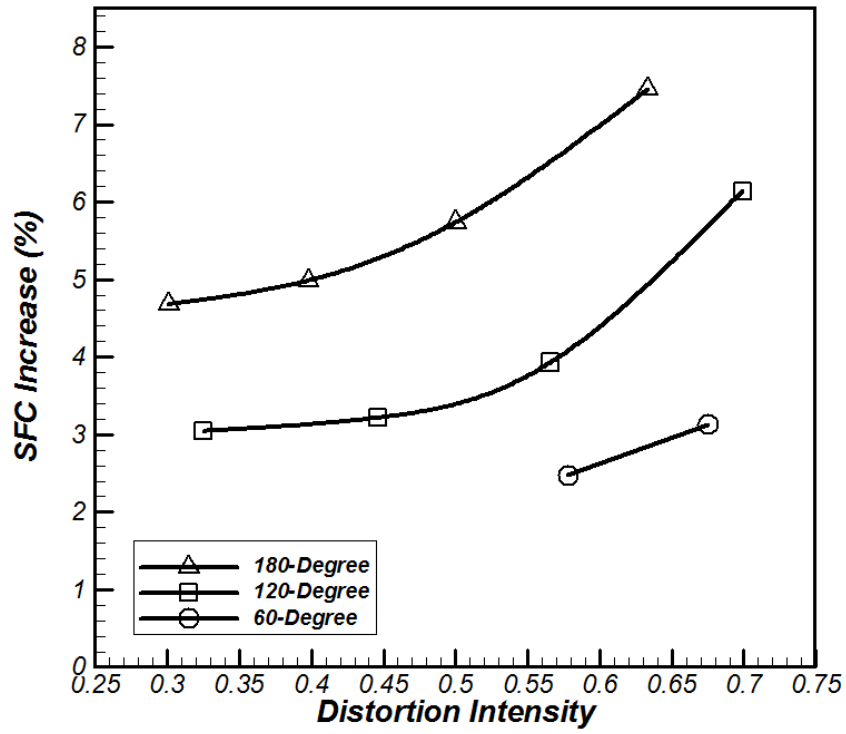

Figure 11: Engine SFC increase due to inlet distortion

The results show a notable deficit in engine performance due to inlet flow distortion. As shown in the pictures, at the most crucial case, the engine faces a thrust deficit of about $5.5 \%$ and SFC increase of about $7.5 \%$.

According to Ref. 2 and 14, the loss in engine performance primarily arises from losses in compression component efficiency and air flow capacity [2, 14]. Engine flow rate is 
not measured in this work and only the behavior of the compression component efficiency is studied. Pressure and temperature sensors at the outlet of the compressor is used to measure the variation of the engine compressor's isentropic efficiency, as described in the previous section.

Due to the sufficient space in compressor, momentum transfer between clean and distorted sections occurs efficiently and it is a reasonable assumption to consider a uniform pressure at the compressor exit $[2,14]$. Therefore it is possible to use only one pressure sensor to measure the exit pressure, as per this experiment.

However, total temperature at the compressor outlet may vary for the clean and distorted sections [2, 14]. Different pressure ratios for distorted and clean sections may convert the low pressure zone at the compressor inlet into a high temperature zone at the outlet. Therefore a total-temperature distortion may exist at the inlet to the burner [14].

In this study a temperature distribution at the compressor outlet is not measured and only one temperature sensor is used at the outlet, due to the lack of space. But because the area between compressor exit and the burner is very small for the current gas turbine (which means rapid heat transfer and thermal equilibrium), and pressure ratio for clean and distorted sections does not differ widely, outlet temperature would not have a significant non-uniformity between clean and distorted sections. Thus the measured temperature at the outlet can be accepted as an average value for calculating the compressor's isentropic efficiency. Figure 12 shows the variation of the isentropic efficiency of the compressor due to inlet flow distortion.

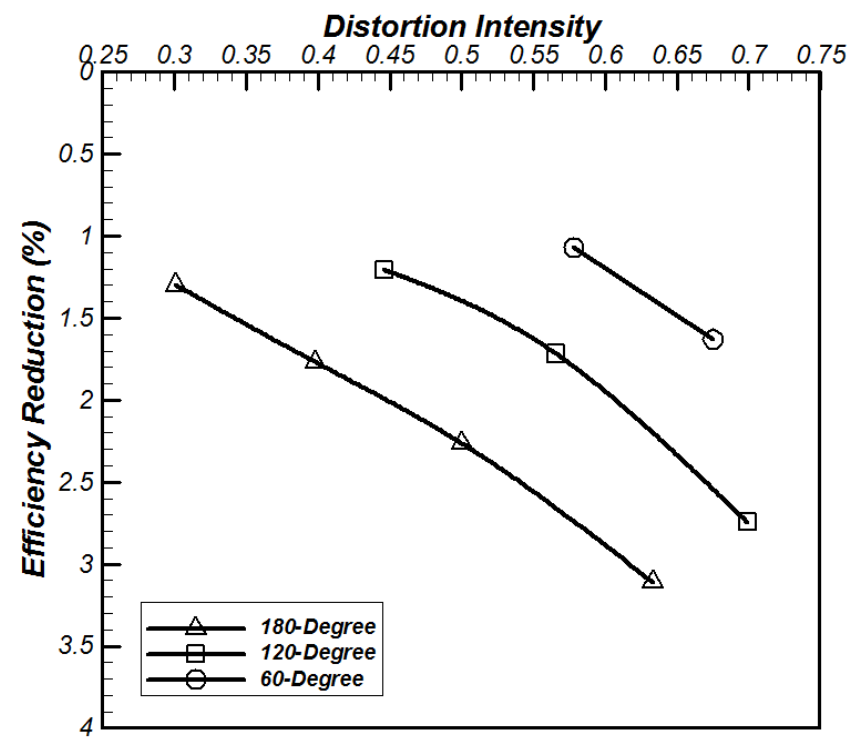

Figure 12: Reduction in compressor's isentropic efficiency due to inlet distortion

Variation of the compressor's isentropic efficiency exhibits a similar trend to the thrust force and engine SFC, which suggests that deterioration of the compressor efficiency due to inlet distortion is indeed a major reason for deterioration of the overall performance of the gas turbine. 


\section{Conclusion}

An experimental study is performed to evaluate performance of a micro gas turbine under inlet total-pressure distortion. Performance measurements under inlet distortion have been carried out and deterioration of engine performance in terms of reduction in engine thrust force and increase in engine SFC is found. Results showed an increase in engine performance loss with increase in both distortion intensity and size.

The most crucial case occurs with 180-degree distorted zone. With distortion intensity of $\mathrm{DC}(180)=0.65$, a thrust deficit of $5.5 \%$ and SFC increase of $7.5 \%$ is found.

Reduction in engine compressor's isentropic efficiency as a source of loss in engine total performance is explained and shown in the test results. A similar trend is found for deterioration of compressor efficiency and the overall engine performance. The results indicate that engine performance can be affected significantly facing intense inlet distortions.

\section{References}

[1] Davis Milt, Alan Hale, Dave Beale, April 2002, "An argument for enhancement of the current inlet distortion ground test practice for aircraft gas turbine engines," ASME Journal of Turbomachinery, Vol. 124, pp. 235-242.

[2] SAE Aerospace Information Report AIR-1419, May 1991, "Inlet Total-Pressure Distortion Considerations for Gas Turbine Engines".

[3] SAE S-16 Committee, ARP 1420, February 2002, "Gas Turbine Inlet Flow Distortion Guidelines," Revision B, Society of Automotive Engineers.

[4] Society of Automotive Engineers, 1991, "A Current Assessment of the Inlet/Engine Temperature Distortion Problem," Aerospace Resource Document ARD50015.

[5] I. Ariga, N. Kasai, S. Masuda, April 1983, "The Effect of Inlet Distortion on Performance Characteristics of a Centrifugal Compressor," ASME Journal of Engineering for Power, Vol. 105, pp. 223-230.

[6] Y. Kim, A. Engeda, R. Aungier and G. Direnzi, May 2001, "The Influence of Inlet Flow Distortion on The Performance of a Centrifugal Compressor and The Development of an Improved Inlet Using Numerical Simulations," Proceedings of The Institution of Mechanical Engineers, Part A: Journal of Power and Energy, Vol. 215, No. 3, pp. 323338.

[7] Drik C. Leinhos, Norbert R. Schmid and Leonhard Fottner, January 2001, "The Influence of Transient Inlet Distortion on the Instability Inception of A Low-Pressure Compressor in A Turbofan Engine," ASME Journal of Turbomachinery, Vol. 123, pp. 1-8. 
[8] Chaoqun Nie, Jingxuan Zhang, Zhiting Tong, Hongwu Zhang, May 2006, "The Response of a Low Speed Compressor on Rotating Inlet Distortion," Journal of Thermal Science, Vol. 15, No. 4, pp. 314-318.

[9] J. Colpin, January 1979, "Propagation of Inlet Flow Distortions through an Axial Compressor Stage," ASME Journal of Engineering for Power, Vol. 101, pp. 116-124.

[10] A. Hale and W. O'Brien, July 1998, "A Three-Dimensional Turbine Engine Analysis Compressor Code (TEACC) for Steady-State Inlet Distortion," ASME Journal of Turbomachinery, Vol. 120, pp. 422-430.

[11] C. Hah, D. C. Rabe, T. J. Sullivan and A. R. Wadia, April 1998, "Effects of Inlet Distortion on The Flow Field in a Transonic Compressor Rotor" ASME Journal of Turbomachinery, Vol. 120, pp. 233-247.

[12] H. Khaleghi, G. Doulgeris, M. Boroomand, P. Pidilis And A. M. Tousi, September 2009, "A Method For Calculating Inlet Distortion Effects On Stability Of Split-Flow Fans," The Aeronautical Journal, Vol. 113, No. 1147, pp. 591-598.

[13] Y. Sheoran, B. Bouldin and P. M. Krishnan, July 2011, "Compressor Performance and Operability in Swirl Distortion," ASME Journal of Turbomachinery, Vol. 134, pp. 0410081-13.

[14] Joachim Kurzke, July 2008, "Effects of Inlet Flow Distortion on the Performance of Aircraft Gas Turbines," ASME Journal of Engineering for Gas Turbines and Power, Vol. 130, 041201-1-7.

[15] Kyungjae Lee, Bohwa Lee, Sanghun Kang, Sooseok Yang, and Daesung Lee, June 2010, "Inlet Distortion Test with Gas Turbine Engine in the Altitude Engine Test Facility," AIAA 2010-4337, $27^{\text {nd }}$ AIAA Aerodynamic Measurement Technology and Ground Testing Conference, Chicago, Illinois.

[16] Beale D. K., Cramer K. B., King P. S. , June 2002, "Development of Improved Methods for Simulating Aircraft Inlet Distortion in Turbine Engine Ground Tests," AIAA 2002-3045, $22^{\text {nd }}$ AIAA Aerodynamic Measurement Technology and Ground Testing Conference, St. Louis, Missouri.

[17] D. Beale, M. Davis and Jim Sirbaugh, May 2006, "Requirements and Advances in Simulating Aircraft Inlet Total-Pressure Distortion in Turbine Engine Group Tests," ASME Turbo Expo 2007: Power for Land, Sea and Air, Barcelona, Spain.

[18] Dave Beale, Milt Davis, Jim Reed and Larry Wilhite, May 2007, "Demonstration Of A Transient Total-Pressure Distortion Generator For Simulating Aircraft Inlet Distortion In Turbine Engine Ground Tests," ASME Turbo Expo 2007: Power for Land, Sea and Air, Montreal, Canada.

[19] B. W. Overall, R. E. Harper, 1977, "The Air Jet Distortion Generator System: A New Tool for Aircraft Turbine Engine Testing," AIAA/SAE $13^{\text {th }}$ Propulsion Conference, Orlando, FL, United States. 
Journal of Engineering for Gas Turbines and Power

[20] M. W. Mcllveen, 1979, "Further Test Results with the Air Jet Distortion Generator System," AIAA/SAE/ASME $15^{\text {th }}$ Joint Propulsion Conference, Las Vegas, NV, United States. 